\title{
LETTER
}

\section{Disruption of Healthcare Amid COVID-19 Pandemic in Bangladesh}

\author{
Hasan Mahmud Reza,", Farhana Sultana ${ }^{2}$ and Isha Olive Khan ${ }^{3}$ \\ ${ }^{\prime}$ Department of Pharmaceutical Sciences, North South University, Bashundhara R/A, Dhaka1229, Bangladesh. \\ ${ }^{2}$ Department of Political Science and Sociology, North South University, Bashundhara R/A, Dhaka1229, Bangladesh. \\ ${ }^{3}$ Department of Pharmacology and Toxicology, Michigan State University, 1129 Farm Lane, East Lansing, MI48824, USA.
}

\begin{abstract}
:
The world is experiencing an unrestrained devastating power of COVID-19. Lack of experience in combating such a pandemic, insufficient medical equipment and professionals, and above all, poor management have led to failure in controlling disease transmission to a large extent in Bangladesh. Therefore, an incredibly high percentage of people may need medical intervention. However, most of the hospitals in the country are not fully ready to cope with the expected surge in critically ill COVID-19 patients. The majority of the private hospitals and some government hospitals are not providing necessary medical care to both COVID-19 and non-COVID-19 patients. Therefore, it is of utmost importance to reinstate the healthcare system to full function to ensure proper treatment to the ailing patients of both COVID-19 and non-COVID-19.
\end{abstract}

Keywords: COVID-19, Non-COVID-19, Hospital, Healthcare, Pandemic, Treatment.

\begin{tabular}{|l|l|l|l|}
\hline Article History & Received: June 6, 2020 & Revised: July 24, 2020 & Accepted: July 26, 2020 \\
\hline
\end{tabular}

\section{INTRODUCTION}

The COVID-19 pandemic has caused more than 6.2 million infections and 0.37 million deaths as of June 01, 2020 worldwide [1]. Most scientists find the non-therapeutic intervention including containment, lockdown, social distancing, quarantine and isolation as an effective way to combat COVID-19 [2]. However, the long-practiced socioculture by humans clashes with these measures, thus the people are non-compliant. Consequently, the highly contagious virus is spreading, and cases of infection are rising exponentially. We observed that disease transmission had occurred very slowly in the first month since COVID-19 was first detected on Mar 08, 2020 [3]. Initially, it was confined in familial clusters. Now, Bangladesh is in the $4^{\text {th }}$ stage of COVID-19 transmission, which means the population is in the arena of massive community transmission [4]. As of June 01,2020 , a total of 49534 cases of COVID-19 have been detected and 672 deaths have been recorded in Bangladesh [3]. The rate of infection is increasing daily as the people are not following social distancing protocols or using face-masks as recommended [2, 5]. The country is likely to observe a huge surge in the number of patients in the upcoming months. The previous report demonstrates that among the total infected patients, $15.7 \%$ develop severe conditions and require hospitalization, oxygen-

Address correspondence to this author at Department of Pharmaceutical Sciences, North South University, Bashundhara R/A, Dhaka 1229, Bangladesh; Tel: +880-2-55668200; Ext.1054; Fax: +880-2-55668202;

E-mail: hasan.reza@northsouth.edu masks and ventilators while $5 \%$ of patients require the ICU [6]. For efficient management and treatment of these COVID-19 patients, all hospitals need to be prepared accordingly.

Another alarming observation is that a large number of non-COVID-19 patients who need emergency medical intervention are not being attended by doctors in most of the hospitals amid the pandemic. A huge number of patients suffering from cancer, cardiovascular disease and kidney disease await immediate care from hospitals for their survival. The lack of knowledge, fear, and shortage of medical-grade personal protection equipment (PPE) have created massive panic among healthcare professionals as well as general people. As a result, many non-COVID-19 patients are discouraged to go to a hospital. On the other hand, doctors are also afraid of coronavirus infection through unknown patients.

We observed a sluggish attitude in the government's overall preparedness. The acute shortage of quality-PPE appeared to be a critical issue that caused more than 1100 healthcare professionals infected. Available data indicates that COVID-19 causes no or only mild and moderate symptoms in more than $80 \%$ of cases $[6,7]$. Most patients recover in $2-4$ weeks, as seen in China [8]. Further evidence shows that some COVID-19 patients who develop severe breathing problems may need to be on ventilators for weeks [9]. As of June 01, 2020, a total of 60181 patients are in quarantine, while 5794 are in isolation [3]. So far, 14 hospitals (COVID-19 hospitals and general hospitals) in Dhaka city and over 10 outside Dhaka 
are rendering services to COVID-19 patients. The health directorate estimates that 30,000 patients may ultimately need hospitalization [10]. However, many hospitals, including COVID-19 ones, do not have a central oxygen supply and a sufficient number of ventilators. The ICUs are not fully equipped to provide complete care to patients with comorbidities and also the number of ICU beds is inadequate. There are only a few hospitals where provisions for admitting both COVID-19 and non-COVID patients have been kept. It is worth mentioning that a local manufacturer is trying to produce ventilators to meet the increased need for the anticipated higher number of patients.

Most of the private hospitals are not continuing their operations now. Even after the government's threat of legal action against those who close privately owned hospitals, clinics and chambers, the owners of these properties ignore such warnings and continue to deny emergency care. When many emergency patients await treatment, the hospital authorities ask patients to bring non-COVID-19 certification, which imparts another level of anxiety. The fact is, while a significant number of private practitioners agree to perform their duties, a large number of them do not, fearing COVID-19 contagion. Many lab technicians are snubbing workplaces, thus halting medical tests in the diagnostic centers. It has been revealed that private hospitals and clinics have no virus testing kit, trained medical personnel or PPE, and so a single coronavirus case at any private hospital may put everyone at risk that can lead to massive panic and chaos. In addition, the national committee for COVID-19 management did not consider private hospitals and clinics on board in handling COVID-19 and thus their amenities such as isolation units, oxygenation systems, frontline treatment teams and separate ICUs are not ready.

Like COVID-19 patients, thousands of non-COVID-19 patients are not obtaining proper medical care from any healthcare center despite the need for emergency medical intervention or surgery. The patients who have general symptoms of simple fever and coughing are the most neglected as most health professionals do not want to consult and interact with such patients. Many doctors, nurses and technicians have lost their confidence in PPE as the initial supply of PPE was of poor quality, which caused COVID-19 infection in several hundred healthcare professionals. As of June 5, 2020, 18 doctors have died of COVID-19. The government is also failing to bring physicians back to their workplace, even after declaring incentives for doctors who attend COVID-19 patients.

\section{CONCLUSION}

To tackle the situation, the public-private cooperation must be improved. There are some good private hospitals mainly located in Dhaka city. These hospitals have better infrastructure with central oxygen supply, ventilators, equipped ICUs and isolated cabins with oxygen supply, etc. A little renovation can make them completely ready to provide necessary care for COVID-19 patients as well as other regular patients. Private hospitals are reluctant to come forward because financial losses are a big factor in the hospital's shareholders' decisions. Considering the need to protect and ensure the benefit of healthcare professionals and hospital staff, and in order to provide regular treatment/medical care and surgery to all other patients as well as COVID-19-infected ones, the government should make an acceptable negotiation so that these hospitals can positively contribute in this hour of crisis. In some cases, the government may take a hardline stance against those who do not come up to help patients in distress amid COVID-19 pandemic. Considering the current pattern of disease transmission, it is speculated that the transmission of COVID-19 will sustain in Bangladesh for quite a long time. Therefore, a realistic and actionable plan will be required to effectively tackle the situation. We recommend the following five points to be implemented immediately to streamline healthcare delivery to both COVID-19 and nonCOVID-19 patients.

(1) All hospitals except COVID-19 ones should be made into two separate wings for treating COVID-19 patients and other types of patients to avoid cross-transmission.

(2) Continuous supply of oxygen has to be ensured in all COVID-19 hospitals. Oxygen cylinders need to be stockpiled in other hospitals where the central oxygen supply is absent.

(3) There is a scarcity of ventilators. The number of ventilators should be increased straightaway. ICU should be equipped with all facilities to treat patients with multiple complications.

(4) There are not enough doctors, respiratory therapists and specialist nurses with the ideal type of critical care expertise. Retired staff should be brought back where possible and existing staff should be adequately trained.

(5) Non-emergency surgeries can be deferred to increase beds in the event of a big surge in coronavirus patients. Extra beds should be placed.

In conclusion, it is accepted that there is a worldwide shortage of equipment and healthcare staff required to manage the catastrophic events caused by the COVID-19 pandemic. It would be truly helpful if the relevant stakeholders especially manufacturers of medical equipment, PPE, sanitizers and those with medical training could volunteer their assistance at the time of this crisis. In response, the government should do everything in its capacity to provide reasonable compensation for these people so that it could better perform in containing the disease and providing ideal healthcare for everyone.

\section{ETHICS APPROVAL AND CONSENT TO PARTICIPATE}

Not applicable.

\section{HUMAN AND ANIMAL RIGHTS}

Not applicable.

\section{CONSENT FOR PUBLICATION}

Not applicable.

\section{AVAILABILITY OF DATA AND MATERIALS}

Not applicable. 


\section{FUNDING}

None.

\section{CONFLICT OF INTEREST}

The author declares no conflict of interest, financial or otherwise.

\section{ACKNOWLEDGEMENTS}

The authors would like to thank Razmin Bari for proofreading and editing.

\section{REFERENCES}

[1] Worldometer. COVID-19 Coronavirus Pandemic June 01 2020.https://www.worldometers.info/coronavirus/

[2] Lewnard JA, Lo NC. Scientific and ethical basis for social-distancing interventions against COVID-19. Lancet Infect Dis 2020; 20(6): 631-3.

[http://dx.doi.org/10.1016/S1473-3099(20)30190-0]

[PMID: 32213329]

[3] Coronavirus disease 2019.https://www.who.int/docs/default-source/ coronaviruse/situation-reports/20200401-sitrep-72-covid-19.pdf

[4] Coronavirus. COVID-19 Dashboard 2020 June 01 2020.http://dashboard.dghs.gov.bd/ webportal/ pages/covid19.php

[5] Feng S, Shen C, Xia N, Song W, Fan M, Cowling BJ. Rational use of face masks in the COVID-19 pandemic. Lancet Respir Med 2020; 8(5): 434-6.

[http://dx.doi.org/10.1016/S2213-2600(20)30134-X] [PMID: 32203710]

[6] Wu Z, McGoogan JM. Characteristics of and important lessons from the coronavirus disease 2019 (COVID-19) outbreak in China: summary of a report of 72314 cases from the Chinese center for disease control and prevention. JAMA 2020.

[http://dx.doi.org/10.1001/jama.2020.2648] [PMID: 32091533]

[7] WHO. Coronavirus disease 2019.https://www.who.int/docs/ defaultsource/coronaviruse/situation-reports/20200401-sitrep-72covid-19.pdf

[8] Bai Y, Yao L, Wei T, et al. Presumed Asymptomatic Carrier Transmission of COVID-19. JAMA 2020; 323(14): 1406-7. [http://dx.doi.org/10.1001/jama.2020.2565] [PMID: 32083643]

[9] Vincent JL, Taccone FS. Understanding pathways to death in patients with COVID-19. Lancet Respir Med 2020; 8(5): 430-2. [http://dx.doi.org/10.1016/S2213-2600(20)30165-X] [PMID: 32272081]

[10] National Guidelines on Clinical Management. 2019. www. mohfw.gov.bd

(C) 2020 Reza et al.

This is an open access article distributed under the terms of the Creative Commons Attribution 4.0 International Public License (CC-BY 4.0), a copy of which is available at: https://creativecommons.org/licenses/by/4.0/legalcode. This license permits unrestricted use, distribution, and reproduction in any medium, provided the original author and source are credited. 